\title{
Analisis SWOT Sebagai Strategi Meningkatkan Daya Saing Pada Apotek 325 Surabaya
}

\author{
Anisa Rachmawati ${ }^{1}$, Ety Dwi Susanti ${ }^{2}$ \\ 1,2Jurusan Administrasi Bisnis, Fakultas Ilmu Sosial dan Ilmu Politik, Universitas Pembangunan Nasional “Veteran” Jawa \\ Timur
}

\begin{tabular}{l}
\hline Article Info \\
\hline Article history: \\
Received 13 Desember 2021 \\
Publish 02 Januari 2022 \\
\\
\hline Keywords: \\
SWOT Analysis \\
Strategy \\
Competitiveness \\
\end{tabular}

\begin{tabular}{l}
\hline Info Artikel \\
\hline Article history: \\
Diterima 13 Desember 2021 \\
Publis 02 Januari 2022
\end{tabular}

\begin{abstract}
This research was conducted at Apotek 325 which is located on Jl. Demak No. 325, Dupak, Krembangan District, Surabaya City, East Java. The pharmacy has been established since 2000 where a new business strategy is needed to face increasing competitive and increasing complex business competition. The research method used is a descriptive quantitative approach, using the SWOT method and data collection techniques with primary data and secondary data, in which the author's secondary data is through in-depth interviews, documentation and participatory observations relating to the SWOT analysis owned by Apotek 325 Surabaya. After getting the data then the data will be analyzed with SWOT. The results of the research from the SWOT analysis obtained IFAS results with a total score of 2.01 while for EFAS results with a total score of 2.49. From the results of the SWOT diagram, Pharmacy 325 is in quadrant II, namely the Diversification Strategy. The results of the SWOT Matrix Strategy obtained that the SO Strategy was 1.7, the ST Strategy was 2.91, the WO Strategy was 1.59, and the WT Strategy was 2.8. ABSTRAK

Penelitian ini dilakukan di Apotek 325 yang berlokasi Jl. Demak No.325, Dupak, Kecamatan Krembangan, Kota Surabaya, Jawa Timur. Apotek sudah berdiri sejak tahun 2000 dimana diperlukan strategi usaha yang baru untuk menghadapi persaingan bisnis yang semakin kompetitif dan semakin kompleks. Metode penelitian yang digunakan adalah pendekatan kuantitatif deskriptif, dengan menggunakan metode SWOT dan teknik pengumpulan data dengan data primer dan data sekunder, yang mana pada data sekunder penulis melalui wawancara mendalam, dokumentasi dan pengamatan berperan serta yang berkaitan dengan Analisis SWOT yang dimiliki oleh Apotek 325 Surabaya. Setelah mendapatkan data kemudian data akan dianalisis dengan SWOT. Hasil penelitian dari analisis SWOT diperoleh hasil IFAS dengan total skor sebesar 2,01 sedangkan untuk hasil EFAS dengan total skore sebesar 2,49. Dari hasil diagram SWOT, Apotek 325 berada pada kuadran II yaitu Strategi Diversifikasi. Hasil pada Strategi Matriks SWOT diperoleh Startegi SO sebesar 1,7, Strategi ST sebesar 2,91, Strategi WO sebesar 1,59, dan Strategi WT sebesar 2,8.
\end{abstract}

This is an open access article under the Lisensi Creative Commons AtribusiBerbagiSerupa 4.0 Internasional

Corresponding Author: Anisa Rachmawati,

Jurusan Administrasi Bisnis, Fakultas Ilmu Sosial dan Ilmu Politik, Universitas Pembangunan Nasional "Veteran" Jawa Timur

Email: nisarch195@gmail.com

\section{PENDAHULUAN}

Di Indonesia khususnya pada sektor bisnis mengalami perkembangan yang sangat pesat, selain itu berkembangnya kemajuan ilmu pengetahuan dan teknologi telah melahirkan era baru dalam 
dunia bisnis. Belakangan ini semakin lama semakin menonjolnya persaingan, perubahan kompleksitas, dan ketidakpastian. Keadaan ini dapat menimbulkan persaingan antara perusahaan yang dikarenakan bertambahnya pesaing bisnis, kebutuhan pasar, volume produk yang terus kian meningkat. Perusahaan harus lebih cermat dalam membaca serta mengantisipasi keadaan pasar agar dapat menciptakan produk yang berkualitas serta dapat memuaskan kebutuhan konsumen sehingga dapat memenangkan persaingan pasar. Kunci suksesnya sebuah perusahaan bersaing tergantung pada penyesuaian secara dinamis terhadap lingkungan yang kompleks dan akan selalu berubahubah.

Apotek 325 salah satu apotek yang dapat bertahan hingga sekarang meskipun masih adanya pesaing dengan bisnis serupa dikarenakan Apotek 325 memimpin pasar di sekitar lokasinya dengan menggunakan strategi biaya rendah (Cost Leadership) dalam menjalankan bisnisnya untuk bersaing dengan pesaingnya terlihat dengan perbandingan harga yang berbeda dengan beberapa produk obat yang di jual di tiga apotek yang dipilih oleh penulis sebagai apotek pembanding yaitu apotek 325 , apotek K24 dan apotek usaha sebagai berikut :

Tabel 1. Daftar Perbandingan Harga Apotek 2021

\begin{tabular}{|l|l|l|l|l|l|}
\hline No & Produk & $\begin{array}{l}\text { Ketegori } \\
\text { Penjualan }\end{array}$ & $\begin{array}{l}\text { Apotek } \\
\mathbf{3 2 5}\end{array}$ & $\begin{array}{l}\text { Apotek } \\
\text { K24 }\end{array}$ & $\begin{array}{l}\text { Apotek } \\
\text { Usaha }\end{array}$ \\
\hline 1 & $\begin{array}{l}\text { Sangobion Vita-Tonik } \\
\text { 250Ml }\end{array}$ & Botol & 28.000 & 33.500 & 30.000 \\
\hline 2 & Nourish Acne Plast 12S & Pcs & 18.500 & 20.800 & 18.550 \\
\hline 3 & Demacolin Sirup 60Ml & Botol & 16.000 & 17.000 & 17.200 \\
\hline 4 & Cortidex 0,5Mg & Tablet & 500 & 401 & 650 \\
\hline 5 & Bioplacenton gel 15Gr & Tube & 21.000 & 29.413 & 21.044 \\
\hline 6 & Destavell 5Mg & Tablet & 65.000 & 95.530 & 75.000 \\
\hline 7 & $\begin{array}{l}\text { Natur E 100IU Soft Caps } \\
\text { 16S }\end{array}$ & Dos/Pack & 20.000 & 20.050 & 21.000 \\
\hline 9 & Enervon-c TAB STR 4'S & Strip & 5.000 & 5.340 & 5.499 \\
\hline 10 & Hot in cream 60Gr & Tube & 42.000 & 46.411 & 46.000 \\
\hline 11 & Insto regular 7,5 ML & Tube & 13.000 & 14.302 & 14.000 \\
\hline 12 & $\begin{array}{l}\text { Vitamin C IPI TAB 45S } \\
\text { Tube }\end{array}$ & Tube & 5.000 & 6.798 & 7.000 \\
\hline 13 & Madu TJ Murni 150Gr & Botol & 16.000 & 23.451 & 16.000 \\
\hline
\end{tabular}

Sumber : Data diolah peneliti, 2021

Dapat dilihat dari tabel tersebut bahwa produk obat yang di jual di ketiga apotek tersebut terlihat bahwa harga yang diberikan oleh apotek 325 lebih murah jika dibandingankan dengan kedua apotek lainnya. Adapun tujuan penelitian ini adalah untuk mengetahui strategi untuk meningkatkan daya saing pada apotek 325 surabaya menggunakan analisis SWOT.

\section{KAJIAN PUSTAKA}

\section{Analisis SWOT}

Analisis SWOT merupakan suatu bentuk analisis dalam upaya untuk penyusunan suatu rencana yang memiliki tujuan jangka pendek maupun jangka panjang. Selain itu bentuk dari analisis SWOT dilihat dari situasi serta kondisi yang bersifat deskriptif atau memberi suatu gambaran yang di mana kondisi dan situasi ini dijadikan sebagai faktor masukan lalu dikelompokkan berdasarkan kontribusinya masing-masingnya. 


\section{Strategi}

Strategi adalah sebuah cara atau teknik yang dilakukan oleh sebuah perusahaan untuk mendapatkan keunggulan bersaing dengan memahami lingkungan internal atau kekuatan dan kelemahan dan lingkungan eksternal peluang dan ancaman, sehingga perusahaan bisa tetap bertahan.

\section{Daya Saing}

Daya saing merupakan kemampuan perusahaan untuk bersaing di pasar yang memiliki kinerja provit jangka panjang dan kemampuan dalam memberikan kompensasi kepada karyawan nyaMserta memberikan pengembalian unggul kepada pemiliknya.

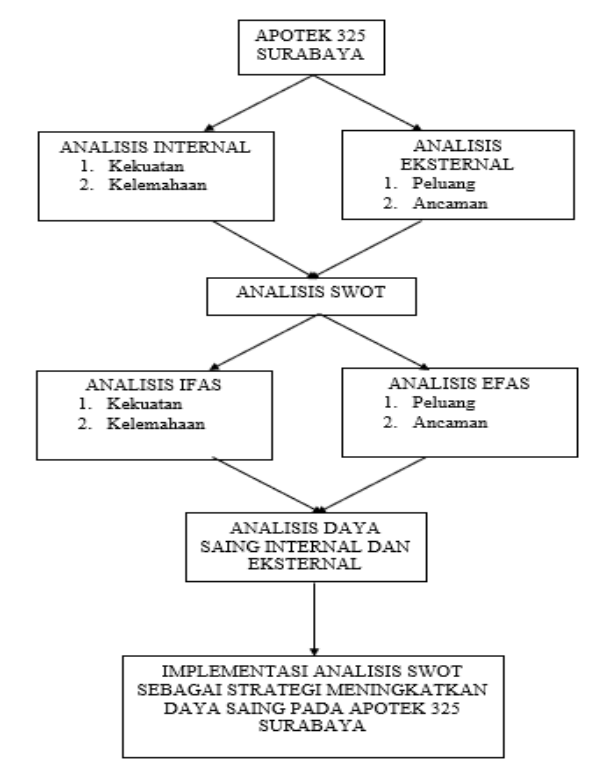

Gambar 1. Kerangka Berpikir

Sumber : Data diolah peneliti, 2021

\section{METODE PENELITIAN}

Jenis penelitian yang digunakan dalam penelitian ini adalah penelitian deskriptif analisis dengan pendekatan kuantitatif. Pada penelitian ini difokuskan untuk meneliti strategi dalam meningkatkan daya saing pada apotek 325 dengan menggunakan analisis SWOT sebagai alat bantu hitung dalam penelitian ini. Pada penelitian ini dilaksanakan disalah satu apotek Surabaya yang bernama Apotek 325 yang berlokasi di J1. Demak No. 325, Dupak, Kecamatan Krembangan, Surabaya, Jawa Timur 60179.

Teknik pengumpulan data yang diambil oleh peneliti untuk memperoleh data yang lengkap, obyektif serta dapat dipertanggung jawabkan kebenarannya serta sesuai dengan penelitian. Data yang digunakan dalam penelitian ini adalah data primer dan data sekunder. Pada teknik pengambilan data peneliti menggunakan beberapa metode pengumpulan data seperti : (1) Pengamatan Berperan Serta (Participant as Observer) (2) Wawancara (Interview) (3) Dokumentasi. Dalam Penelitian ini menggunakan metode analisis deskriptif serta pada analisisnya menggunakan Analisis SWOT. Data yang dihasilkan melalui metode analisis deskriptif berasal dari pengamatan berperan serta (Perticipan as Observer), Wawabcara (Interview) dan Dokumentasi yang berkaitan dengan strategi meningkatkan daya saing pada Apotek 325 Surabaya.

\section{HASIL PENELITIAN DAN PEMBAHASAN 4.1.Hasil Penelitian Profil Perusahaan}


Apotek 325 Surabaya merupakan bisnis yang bergerak dalam peredaran obat yang sudah berdiri sejak tahun 2000. Tujuan didirikannya apotek 325 Surabaya adalah dikarenakan sekitar didaerah Demak belum terdapat sebuah apotek yang berdiri didaerah tersebut. Dengan berdirinya apotek 325 disekitar daerah Demak Surabaya diharapkan dapat membantu masyarakat sekitar dalam menemukan obat yang diperlukan oleh pasien ataupun pelanggan tentunya dengan harga yang terjangkau dan lokasi yang dekat.

Apotek 325 memiliki jumlah karyawan sebanyak 9 orang yang terdiri dari 2 orang bagian kasir untuk dua shift, 4 orang bagian pelayanan pelanggan, 2 orang bagian obat dengan resep, dan 1 orang bagian apoteker.

Nama Perusahaan : Apotek 325 Surabaya

Lokasi : Jl. Demak No. 325, Dupak, Kecamatan Krembangan, Surabaya, Jawa Timur 60179

Jam Operasional : Buka setiap hari mulai pukul 07:15 - 22:00 kecuali hari minggu mulai pukul 07:15 - 21:30.

\section{Hasil IFAS}

Tabel 2. Hasil EFAS (Eksternal Strategy Factors Analysis Summary)

\begin{tabular}{|c|c|c|c|c|}
\hline No & $\begin{array}{l}\text { Faktor-faktor } \quad \text { Strategi } \\
\text { Internal }\end{array}$ & Bobot & Rating & Bobot x Rating \\
\hline & Kekuatan (Strength) & & & \\
\hline 1 & Harga yang lebih murah & 0,17 & 2 & 0,34 \\
\hline 2 & $\begin{array}{l}\text { Pelayanan dan fasilitas yang } \\
\text { diberikan cukup baik }\end{array}$ & 0,08 & 1 & 0,08 \\
\hline 3 & $\begin{array}{lll}\begin{array}{l}\text { Keragaman produk yang } \\
\text { bervariasi }\end{array} & \\
\end{array}$ & 0,16 & 2 & 0,32 \\
\hline 4 & Lokasi yang strategis & 0,09 & 1 & 0,09 \\
\hline 5 & $\begin{array}{l}\text { Memiliki ijin perundang- } \\
\text { undangan. }\end{array}$ & 0,10 & 1 & 0,10 \\
\hline 6 & $\begin{array}{l}\text { Pembayaran bisa dilakukan } \\
\text { secara tunai maupun non tunai }\end{array}$ & 0,06 & 1 & 0,06 \\
\hline \multirow[t]{2}{*}{7} & $\begin{array}{l}\text { Memiliki ijin perundang- } \\
\text { undangan. }\end{array}$ & 0,07 & 1 & 0,07 \\
\hline & Total & $\mathbf{0 , 7 3}$ & & 1,06 \\
\hline \multirow[t]{2}{*}{ No } & $\begin{array}{l}\text { Faktor }- \text { faktor Strategi } \\
\text { Internal }\end{array}$ & Bobot & Rating & Bobot x Rating \\
\hline & Kelemahan (Weakness) & & & \\
\hline 1 & $\begin{array}{l}\text { Akamedis yang kurang dari } \\
\text { karyawan }\end{array}$ & 0,12 & 3 & 0,35 \\
\hline 2 & $\begin{array}{l}\text { Belum bekerja sama dengan } \\
\text { pihak asuransi atau bpjs }\end{array}$ & 0,10 & 4 & 0,40 \\
\hline 3 & $\begin{array}{l}\text { Kurangnya brand image kepada } \\
\text { masyarakat luas }\end{array}$ & 0,05 & 4 & 0,20 \\
\hline & Total & $\mathbf{0 , 2 7}$ & & $\mathbf{0 , 9 5}$ \\
\hline & Total Skor Internal & 1,00 & & 2,01 \\
\hline
\end{tabular}

Sumber : Hasil olahan data oleh peneliti 2021

Dari hasil Tabel diatas hasil olahan data IFAS, faktor kekuatan internal memiliki skor sebesar 1,06 dan faktor kelemahan internal memiliki skor sebesar 0,95. Sedangkan hasil analisis matriks IFAS pada Apotek 325 Surabaya mencangkup keseluruhan faktor internal yang terdiri dari kekuatan (Strength) dan kelemahan (Weakness) dengan total skor sebesar 2,01 yang berarti 
Apotek 325 Surabaya memiliki kekuatan internal yang saat tinggi dimana yang dapat dimanfaatkan untuk keberlangsungan usahanya.

\section{Hasil EFAS}

Tabel 3. Hasil EFAS (Eksternal Strategy Factors Analysis Summary)

\begin{tabular}{|c|c|c|c|c|}
\hline No & Faktor - faktor Strategi Internal & Bobot & Rating & Bobot x Rating \\
\hline & Peluang (Opportunity) & & & \\
\hline 1 & $\begin{array}{l}\text { Adanya praktek dokter disekitar } \\
\text { apotek }\end{array}$ & 0,03 & 1 & 0,03 \\
\hline 2 & Adanya wabah penyakit. & 0,12 & 2 & 0,24 \\
\hline 3 & $\begin{array}{l}\text { Obat merupakan produk yang } \\
\text { dibutuhkan. }\end{array}$ & 0,09 & 1 & 0,09 \\
\hline 4 & $\begin{array}{l}\text { Kesadaran masyarakat yang tinggi } \\
\text { akan Kesehatan }\end{array}$ & 0,07 & 1 & 0,07 \\
\hline 5 & Luasnya pangsa pasar & 0,08 & 2 & 0,16 \\
\hline \multirow[t]{2}{*}{6} & $\begin{array}{lll}\text { Penjualan produk yang } & \text { bisa } \\
\text { dilakukan di marketplace } & \text { lain } \\
\text { seperti Halodoc. } & & \\
\end{array}$ & 0,05 & 1 & 0,05 \\
\hline & Total & 0,44 & & 0,64 \\
\hline \multirow[t]{2}{*}{ No } & Faktor - faktor Strategi Internal & Bobot & Rating & Bobot x Rating \\
\hline & Ancaman (Threaths) & & & \\
\hline 1 & $\begin{array}{l}\text { Adanya pesaing offline yang } \\
\text { berada di dekat apotek } 325\end{array}$ & 0,10 & 3 & 0,30 \\
\hline 2 & Harga obat yang fluktuatif & 0,10 & 4 & 0,40 \\
\hline 3 & Rumitnya perijinan apotek & 0,08 & 4 & 0,32 \\
\hline 4 & $\begin{array}{lll}\text { Kebijakan distributor } & \text { yang } \\
\text { memperumit pengembalian } & \text { obat } \\
\text { dan alat Kesehatan. } & \\
\end{array}$ & 0,13 & 3 & 0,38 \\
\hline 5 & $\begin{array}{l}\text { Adanya pesaing online karena } \\
\text { apotek } 325 \text { sudah mendaftarkan } \\
\text { diri di marketplace shoppe dan } \\
\text { tokopedia }\end{array}$ & 0,15 & 3 & 0,45 \\
\hline & Total & $\mathbf{0 , 5 6}$ & & $\mathbf{1 , 8 5}$ \\
\hline & Total Skor Eksternal & $\mathbf{1 , 0 0}$ & & 2,49 \\
\hline
\end{tabular}

Sumber : Data diolah peneliti, 2021

Dari hasil Tabel 3 Hasil olahan data EFAS, faktor peluang eksternal memiliki skor sebesar 0,64 dan faktor ancaman eksternal memiliki skor sebesar 1,85. Sedangkan hasil analisis matriks EFAS pada Apotek 325 Surabaya mencangkup keseluruhan faktor eksternal yang terdiri dari peluang (Opportunity) dan ancaman (Threaths) dengan total skor 2,49 yang berarti ancaman yang dihadapi oleh Apotek 325 sangat tinggi, maka dari itu perlunya terus memanfaatkan peluang yang ada agar dapat meminimalisir ancaman yang tinggi agar tetap dapat bertahan dan bersaing di bisnis yang serupa.

\section{Diagram SWOT}




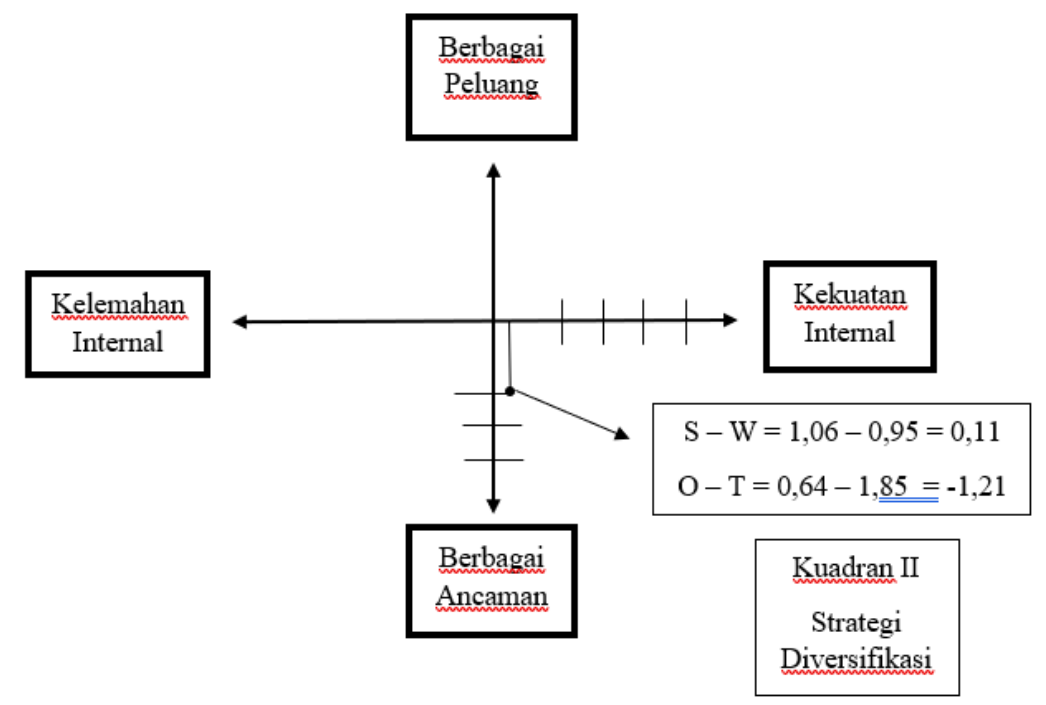

Gambar 2. Diagram Kuadran Hasil Analisis SWOT Sumber : Data diolah peneliti, 2021

Berdasarkan pengolahan data pada gambar 4.4 diagram analisis SWOT maka startegi yang tepat untuk digunakan oleh Apotek 325 adalah strategi Diversifikasi yang terletak pada kuadran II. Strategi Diversifikasi yaitu dengan membuat strategi baru bahkan yang lain dari biasanya dimana dengan memanfaatkan kekuatan internal Apotek 325 yang diharapkan dapat memungkinkan terciptanya peluang baru. Meskipun Apotek mendapat berbagai ancaman, namun hingga saat ini Apotek 325 dapat bertahan karena memiliki kekuatan dari segi internal Apotek 325.

\section{Rumusan Strategi matriks SWOT}

Tabel 4. Rumusan Strategi Matriks SWOT

\begin{tabular}{|l|l|l|}
\hline \multicolumn{1}{|c|}{ IFAS } & Kekuatan (Strength) & Kelemahan (Weakness) \\
\hline $\begin{array}{l}\text { Peluang } \\
\text { (Opportunity) }\end{array}$ & Strategi SO (Strengths & $\begin{array}{l}\text { Strategi WO (Weakness } \\
\text { Opportunity) } \\
1,06+0,64=1,7\end{array}$ \\
\hline Opportunity) \\
Ancama & Strategi ST (Strength Treaths) & Stretegi WT (Weakness \\
(Treaths) & $1,06+1,85=2,91$ & Treaths) \\
& & $0,95+1,85=2,8$ \\
\hline
\end{tabular}

Sumber : Data diolah peneliti, 2021

\section{Perencanaan Kombinasi Strategi SWOT}

Tabel 5. Perencaam Kombinasi Strategi SWOT

\begin{tabular}{|l|l|l|}
\hline \multicolumn{1}{|c|}{ IFAS } & Kekuatan (Strength) & Kelemahan (Weakness) \\
\hline $\begin{array}{l}\text { EFAS } \\
\text { (Opportunity) }\end{array}$ & $\begin{array}{l}\text { Strategi SO (Strength } \\
\text { Opportunity) }\end{array}$ & $\begin{array}{l}\text { Strategi WO (Weakness } \\
\text { Opportunity) }\end{array}$ \\
& Menggunakan & Meminimalisir \\
\hline
\end{tabular}




\begin{tabular}{|l|l|l|}
\hline & $\begin{array}{l}\text { kekuatan untuk } \\
\text { memanfaatkan } \\
\text { peluang=1,7 }\end{array}$ & $\begin{array}{l}\text { kelemahan untuk } \\
\text { memanfaatkan peluang } \\
=1,59\end{array}$ \\
\hline $\begin{array}{l}\text { Ancaman } \\
\text { (Treats) }\end{array}$ & $\begin{array}{l}\text { Strategi ST (Strength } \\
\text { Treaths) }\end{array}$ & $\begin{array}{l}\text { Stretegi WT (Weakness } \\
\text { Treaths) }\end{array}$ \\
& $\begin{array}{l}\text { Menggunakan } \\
\text { kekuatan untuk } \\
\text { meminimalisir atau } \\
\text { menghindari ancaman } \\
=2,91\end{array}$ & $\begin{array}{l}\text { Meminimalkan } \\
\text { kelemahan untuk } \\
\text { menghindari ancaman } \\
=2,8\end{array}$ \\
\hline
\end{tabular}

Sumber : Data diolah peneliti, 2021

\section{Rumusan Alternatif Strategi SWOT}

Tabel 6. Rumusan Alternatif Strategi SWOT

\begin{tabular}{|c|c|c|}
\hline EFAS & $\begin{array}{l}\text { Kekuatan (Strength) } \\
\text { 1. Harga yang lebih murah } \\
\text { 2. Pelayanan dan fasilitas } \\
\text { yang diberikan cukup baik } \\
\text { 3. Keragaman produk yang } \\
\text { bervariasi } \\
\text { 4. Lokasi yang strategis } \\
\text { 5. Memiliki ijin perundang- } \\
\text { undangan. } \\
\text { 6. Pembayaran bisa dilakukan } \\
\text { secara tunai maupun non } \\
\text { tunai } \\
\text { 7. Memiliki ijin perundang- } \\
\text { undangan. }\end{array}$ & $\begin{array}{l}\text { Kelemahan (Weakness) } \\
\text { 1. Akamedis yang kurang dari } \\
\text { karyawan. } \\
\text { 2. Belum bekerja sama } \\
\text { dengan pihak asuransi atau } \\
\text { BPJS. } \\
\text { 3. Kurangnya brand image } \\
\text { kepada masyarakat luas }\end{array}$ \\
\hline $\begin{array}{l}\text { Peluang } \\
\text { (Opportunity) } \\
\text { 1. Adanya praktek } \\
\text { dokter disekitar apotek } \\
\text { 2. Adanya wabah } \\
\text { penyakit. } \\
\text { 3. Obat merupakan } \\
\text { produk } \\
\text { dibutuhkan. } \\
\text { 4. } \quad \text { Kang } \\
\text { masyarakat yang tinggi } \\
\text { akan Kesehatan. } \\
\text { 5. Luasnya pangsa } \\
\text { pasar } \\
6 . \quad \text { Penjualan produk } \\
\text { yang bisa dilakukan di } \\
\text { marketplace lain seperti } \\
\text { halodoc. } \\
\end{array}$ & $\begin{array}{l}\text { Strategi SO } \\
\text { (Menggunakan kekuatan } \\
\text { untuk memanfaatkan } \\
\text { peluang) } \\
\text { 1. adanya penambahan } \\
\text { layanan praktek dokter pada } \\
\text { apotek akan mempermudah } \\
\text { konsumen serta menambah } \\
\text { pemasukan untuk apotek. } \\
\text { 2. luasnya pangsa pasar yang } \\
\text { didukung oleh harga jual } \\
\text { produk pada apotek l;ebih } \\
\text { murah dari pada pesaing, } \\
\text { yang mana akan membuat } \\
\text { konsumen terus berdatangan } \\
\text { karena obat merupakan } \\
\text { produk yang dibutuhkan di } \\
\text { kala sakit. }\end{array}$ & $\begin{array}{l}\text { Strategi WO } \\
\text { (Meminimalisir kelemahan } \\
\text { untuk memanfaatkan } \\
\text { peluang) } \\
\text { 1. kesadaran masyarakat yang } \\
\text { tinggi akan kesehatan maka } \\
\text { perlunya apotek kerjasama } \\
\text { dengan pihak asuransi seperti } \\
\text { BPJS atau asuransi swasta } \\
\text { akan mempermudah pasien } \\
\text { dalam menebus obat. } \\
\text { 2. Luasnya pangsa pasar } \\
\text { dapat dimanfaatkan untuk } \\
\text { meningkatkan brand image } \\
\text { apotek kepada masyarakat } \\
\text { luas. }\end{array}$ \\
\hline Ancaman (Treaths) & Strategi ST & Strategi WT \\
\hline
\end{tabular}




\begin{tabular}{|c|c|c|}
\hline $\begin{array}{l}\text { 1. Adanya pesaing } \\
\text { offline yang berada di } \\
\text { dekat apotel } 325 \\
\text { 2. Harga obat yang } \\
\text { fluktuatif. } \\
\text { 3. Rumitnya perijinan } \\
\text { apotek. } \\
\text { 4. Kebijakan distributor } \\
\text { yang memperumit } \\
\text { pengembalian obat dan } \\
\text { alat Kesehatan. } \\
\text { 5. Adanya pesaing } \\
\text { online karena apotek } \\
\text { 325 sudah } \\
\text { mendaftarkan diri di } \\
\text { marketnlace shonne dan }\end{array}$ & $\begin{array}{l}\text { (Menggunakan kekuatan } \\
\text { untuk meminimalisir atau } \\
\text { menghindari ancaman) } \\
\text { 1. Harga yang lebih murah } \\
\text { dapat menjadikan apotek } \\
\text { melawan pesaing disekitar. } \\
2 \text { melaksanakan } \\
\text { pembaharuan terhadap } \\
\text { perundang-perundangan agar } \\
\text { dapat terus menjalankan } \\
\text { bisnis apotek. }\end{array}$ & $\begin{array}{l}\text { (Meminimalkan kelemahan } \\
\text { untuk menghindari ancaman) } \\
1 \text { dengan memberikan } \\
\text { wawasan atau merekrut } \\
\text { karyawan yang sudah banyak } \\
\text { memiliki akamedis atau } \\
\text { pengalaman dibidangnya } \\
\text { akan mengurangi rumitnya } \\
\text { perijinan mendirikan apotek. }\end{array}$ \\
\hline
\end{tabular}

Sumber : Data diolah peneliti, 2021

\subsection{Pembahasan}

\section{Hasil Analisis SWOT}

Pada hasil analisis data melalui matriks IFAS dan EFAS yang diperoleh menunjukan bahwa Apotek 325 Surabaya memiliki bobot yang baik pada lingkungan internalnya yaitu pada posisi kekuatan (Strength) dan dalam bobot yang kurang baik pada lingkungan eksternalnya yaitu pada posisi ancaman (Treaths), sehingga dapat disimpulkan bahwa posisi diagram SWOT berada pada posisi kuadran II (Dua) yaitu strategi diversifikasi, yang mana bisnis apotek 325 ini meskipun menghadapi berbagai ancaman, apotek 325 memiliki kekutan yang cukup dari segi internalnya. Maka strategi yang perlu dilakukan oleh apotek 325 adalah strategi diversifikasi dengan menggunakan kekuatan untuk memanfaatkan peluang jangka panjang (Strategi ST) dengan membuat startegi yang berbeda dengan memanfatkan kekuatan internal yang akan memungkinkan terciptanya peluang dimasa akan datang.

Berdasarkan Analisa di atas bahwa kinerja Apotek 325 dapat ditentukan oleh kombinasi faktor internal dan eksternal yang ditunjukkan dalam tabel matriks SWOT. Berikut ini hasil Analisa penulis berdasarkan matriks SWOT diatas :

\section{Strategi SO ( Strength - Opportunity)}

Strategi ini merupakan gabungan dari faktor internal kekuatan (Strength) dan faktor eksternal peluangn (Opportunity), yaitu dengan memanfaatkan seluruh kekuatan internal perusahaan dalam memanfaatkan peluang sebanyak-banyaknya. Strategi SO yang ditempuh pada Apotek 325 Surabaya yaitu :

a. Adanya penambahan layanan praktek dokter pada apotek akan mempermudah konsumen serta menambah pemasukan untuk apotek.

b. Luasnya pangsa pasar yang didukung oleh harga jual produk pada apotek 1;ebih murah dari pada pesaing, yang mana akan membuat konsumen terus berdatangan karena obat merupakan produk yang dibutuhkan di kala sakit.

\section{Strategi ST (Strength - Threats )}

Strategi ini merupakan gabungan dari faktor internal kekuatan (Strength) dan faktor eksternal ancaman (Treats), yaitu dengan memanfaatkan seluruh kekuatan internal perusahaan 
dalam untuk mengatasi berbagai ancaman dari luar perusahaan. Strategi ST yang ditempuh pada Apotek 325 Surabaya yaitu :

a. Harga yang lebih murah dapat menjadikan apotek melawan pesaing disekitar.

b. Melaksanakan pembaharuan terhadap perundang-perundangan agar dapat terus menjalankan bisnis apotek.

\section{Strategi WO (Weakness - Opportunity )}

Strategi ini merupakan gabungan dari faktor internal kelemahan (Weakness) dan faktor eksternal peluang (Opportunity), yaitu dengan memanfaatkan peluang sebnyak mungkin untuk meminimalisir kelemahan yang dimiliki perusahaan. Strategi WO yang ditempuh pada Apotek 325 Surabaya yaitu :

a. Kesadaran masyarakat yang tinggi akan kesehatan maka perlunya apotek kerjasama dengan pihak asuransi seperti BPJS atau asuransi swasta akan mempermudah pasien dalam menebus obat.

b. Luasnya pangsa pasar dapat dimanfaatkan untuk meningkatkan brand image apotek kepada masyarakat luas.

\section{Strategi WT (Weakness - Threats )}

Strategi ini merupakan gabungan dari faktor internal kelemahan (Weakness) dan faktor eksternal ancaman (Treats), yaitu dengan menghindari ancaman dari luar perusahaan untuk mengurangi kelemahan yang dimiliki perusahaan. Strategi WT yang ditempuh pada Apotek 325 Surabaya yaitu :

Dengan memberikan wawasan atau merekrut karyawan yang sudah banyak memiliki akamedis atau pengalaman dibidangnya akan mengurangi rumitnya perijinan mendirikan apotek.

\section{Faktor yang mempengaruhi daya saing}

a. Lokasi : lokasi sangat strategis mempengaruhi apotek 325 yang dapat membantunya bertahan dengan persaingan bisnis yang terjadi. Lokasi startegis merupakan faktor pertama kerberlangsungan usaha, karena jika lokasi strategis maka dapat dengan cepat menarik perhatian konsumen serta dapat dengan mudah di akses oleh konsumen yang ingin hendak berkunjung ke Apotek 325.

b. Harga : harga yang diberikan kepada konsumen cukup terjangkau, salah satu yang membuat apotek 325 dapat bertahan hingga saat ini adalah dikarenakan harga yang dijualkan kepda konsumen lebih murah jika dibandingkan dengan apotek/pesainng bisnis serupa disekitar wilyah Apotek 325 Surabaya.

c. Pelayanan/service : Pelayanan yang diberikan apotek 325 kepada konsumen sangat baik karena diharapkan jika pelaku bisnis melakukan pelayanan yang baik diharapkan dapat membuat konsumen merasa nyaman serta mendapatkan kepercayaan dari konsumen dalam pembelian produk secara berulang kali atau berkala.

\section{Strategi generik menurut Michel A. Porter (2007)}

Pada Apotek 325 menurut teori Michel A. Porter menurut penulis Apotek 325 masuk dalam kategori Strategi biaya rendah (Cost Leadership). Karena strategi tersebut yang digunakan oleh apotek dalam persaingan bisnisnya. Strategi ini menekan biaya produk per unit sangat rendah yang mampu membuat apotek 325 menjadi pemimpin pasar dalam menentukan harga dan memastikan tingkat keuntungan pasar tinggi dengan cara yang agresif, efisiensi, dan kefektifan biaya.

\section{KESIMPULAN}

Melalui penelitian ini, peneliti berhasil menarik kesimpulan berdasarkan hasil analisis SWOT yang telah dilaksanakan sebagai berikut :

a. Hasil analisis dengan matriks IFAS dari faktor internal kekuatan sebesar 1,06 serta faktor internal kelemahan sebesar 0,95 maka jumlah skore nilai IFAS sebesar 2,01. Sedangkan hasil analisis 
EFAS dari faktor eksternal peluang sebesar 0,64 serta faktor eksternal ancaman sebesar 1,85, maka jumlah skore EFAS sebesar 2,49.

b. Hasil diagram SWOT menunjukkan bahwa Apotek 325 berada pada kuadran II (Dua) yaitu strategi divesifikasi, dimana kuadran tersebut menunjukan jika apotek 325 menghadapi berbagai ancaman namun dapat diatasi dengan kekuatan internal yang dimiliki Apotek 325 Surabaya. Strategi yang perlu diterapkan adalah dengan menggunakan kekuatan internal untuk memanfaatkan peluang yang ada dengan cara membuat stategi yang berbeda dengan memanfaatkan kekuatan internal sehingga akan memungkinkan terciptanya peluang. Strategi tersebut menandakan keadaan perusahaan yang kuat dan mempu untuk terus bertahan serta menghadapi persaingan hingga saat ini meskipun adanya berbagai ancaman yang datang.

c. Hasil dari rumusan strategi matriks SWOT adalaha Apotek 325 Surabaya cenderung ke strategi ST atau menciptakan strategi yang menggunakan kekuatan untuk mengatsi ancaman dengan memiliki nilai tertinggi sebesar 2,91. Strategi ST Apotek 325 Surabaya adalah :

1) Memberikan harga yang terbaik dapat menjadikan apotek dapat melawan pesaing.

2) Melakukan pembaharuan terhadap perundang - undangan agar dapat terus menjalankan usaha

3) Menambah layanan fasilitas yang yang baik dan nyaman untuk lebih mempermudah pelanggan untuk mengunjungi Apotek 325

\section{SARAN}

Berdasarkan hasil penelitian yang telah dilaksanakan dan kesimpulan yang telah dikemukakan, maka peneliti memberikan beberapa saran sebagai bahan pertimbangan dalam mengambil sebuah keputusan :

a. Melakukan pelatihan bagi karyawan agar dapat menambah wawasan tentang akamedis atau bisa melakukan perekrutan karyawan dengan minimal sudah menempuh Pendidikan D3 atau S1 dengan jurusan apoteker.

b. Melakukan perluasan pangsa pasar dengan cara promosi yang lebih dimaksimalkan agar Apotek 325 dapat lebih dikenal masyarakat yang lebih luas agar dapat meningkatkan brand image Apotek 325 diantaranya dengan cara promo disetiap akhir bulan atau promo buy one get one dan influencer marketing.

c. Menambah mitra kerja sama dengan distributor lain untuk meminimalisir susahnya pengembalian obat.

d. Penambahan fasilitas agar mempermudah pelanggan dalam mengunjungi Apotek 325, seperti bekerjasama dengan dokter setempat dan bekerja sama dengan pihak asuransi yang dapat mempermudah pelanggan jika menebus obat dengan pihak asuransi swasta atau BPJS Kesehatan (Badan Penyelenggara Jaminan Sosial Kesehatan).

\section{DAFTAR PUSTAKA}

Arif Yusuf Hamali. (2016). Pemahaman Strategi Bisnis dan Kewirausahaan.

Freddy Rangkuti. (2004).Analisis SWOT Teknik Membedah Kasus Bisnis, (Jakarta: PT. GramediaPustaka Utama, 2004).

Freddy Rangkuti. (2004).Swot Balanced Scorecard, Teknik Menyusun Strategi Korporat yang Efektif.

Freddy Rangkuti. (2011).Mengelola Kinerja dan Risiko (Jakarta: PT Gramedia Pustaka Utama).

Freddy Rangkuti.David. (2011). Manajemen Strategis Konsep. Buku 1. Edisi 12. (Jakarta: Salemba Empat.

Gunawan, Imam. (2016). Metodologi Penelitian Kualitatif: Teori dan Praktik. Jakarta: Bumi Aksara.

Micel E. Porter. (2001). Competitive Advantage. Edisi Bahasa Indonesia. (Jakarta: PT. Indeks Kelompok Gramedia, edisi 4.

Moleong, Lexy J. (2014). Metedologi Penelitian Kualitatif. Bandung: PT. Remaja Rosdakarya. 
Sedarmayanti.Refika Aditama (2004). Manajemen Strategi.

Silalahi, U. Refika Aditama.(2015). Metode Penelitian Kuantitatif. Bandung.

Sugiyono.Alfabeta. (2017). Metode Penelitian Kuantitatif, Kualitatif dan R\&D.

Yulihar Diyanti. (2018). Analisis Swot Sebagai Strategi Meningkatkan Daya Saing Usaha Tahu Di Desa Hajoran Kecamatan Sungai Kanan Kabupaten Labuhan Batu Selatan. (http://repository.uinsu.ac.id/4672/)

Juni Ivana Sinaga. (2020). Analisis Swot Sebagai Strategi Meningkatkan Daya Saing Pada Pt. Sunthi Sepuri Medan. (http://jurnalstipro.com/wp-content/uploads/2020/07/6-Juni-IvanaSinaga-1.pdf)

Endang Naryono. (2018).Analisis Swot Sebagai Dasar Strategi Meningkatkan Daya Saing Pada Anugrah Hotel

Sukabumi. (https://journal.stiepasim.ac.id/index.php/ekonomedia/article/view/43)

Silvia Rahmawati,Sutantri. (2019). Analisis SWOT Sebagai Strategi Meningkatkan Daya Saing Bisnis Toko Surabaya Ampel Kota Kediri.

(https://www.ejournal.iai-tribakti.ac.id/index.php/perbankan/article/view/1061)

Chintya Armi Kasmiruddin. (2019).Analisis Swot Sebagai Strategi Meningkatkan Daya Saing Pada Bisnis Usaha Sepatu (Kasus Toko Sepatu Stars Cabang Marpoyan Pekanbaru). (https://jom.unri.ac.id/index.php/JOMFSIP/article/view/2448). 